\title{
INTEGRATION OF SATELLITE-RETRIEVED SOIL MOISTURE OBSERVATIONS WITH A GLOBAL TWO-LAYER SOIL MOISTURE MODEL
}

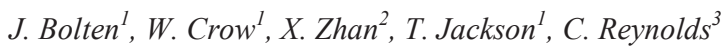 \\ ${ }^{1}$ USDA-ARS Hydrology and Remotes Sensing Lab, Bldg. 007 \\ BARC-West, Beltsville, MD 20705 \\ ${ }^{2}$ NOAA NESDIS Center for Satellite Applications and Research, \\ Camp Springs, MD 20746 \\ ${ }^{3}$ USDA-FAS Production Estimate and Crop Assessment Divisin \\ Washington, DC 20250
}

\begin{abstract}
Global estimates of soil moisture are a large component of crop yield fluctuations provided by the US Department of Agriculture (USDA) Production Estimation and Crop Assessment Division (PECAD). The current system utilized by PECAD estimates soil moisture from a 2-layer water balance model based on daily precipitation and temperature data. However, many regions of the globe lack climate observations at the temporal and spatial resolutions required by PECAD. This study integrates NASA's soil moisture remote sensing product provided by the EOS Advanced Microwave Scanning Radiometer (AMSR-E) into the U.S. Department of Agriculture Crop Assessment and Data Retrieval (CADRE) decision support system. An Ensemble Kalman Filter (EnKF) has been designed to optimally merge the AMSR-E observations with the PECAD soil moisture outputs when available. A methodology of system design and an evaluation of the system performance over the Conterminous United States (CONUS) is presented.
\end{abstract}

Index Terms - Remote sensing, soil moisture, data assimilation

\section{INTRODUCTION}

The U.S. Department of Agriculture (USDA) Production Estimates and Crop Assessment Division (PECAD) is responsible for providing monthly global crop estimates. These global crop estimates are used to increase agricultural efficiency, influence global commodity market access and provide early warning of production changes and agricultural drought monitoring. In addition to crop forecasting for food security, global agricultural monitoring has also been shown to be useful for estimating the effects of climate change on global food supplies and agriculturally-driven environmental changes [1,2].

In an effort to determine anomalous conditions indicating times of water stress or flooding, PECAD analysts compare current global conditions against a database of archived satellite imagery and crop yields. Estimates from PECAD are derived from a merging of many data sources including satellite and ground observations, and more than 20 years of climatology and crop behavior data over key agricultural areas. To most efficiently manage the data sources, PECAD has developed a series of analytical tools, crop models, and hazard calendars within a Crop
Condition Data Retrieval and Evaluation (CADRE) Data Base Management System (DBMS). The goal of CADRE is to provide timely and accurate estimates of global crop conditions for use in up-to-date commodity intelligence reports.

A crucial requirement of these global crop yield forecasts is the regional characterization of surface and sub-surface soil moisture. However, due to the spatial heterogeneity and dynamic nature of precipitation events and soil wetness, accurate estimation of regional land surface-atmosphere interactions based sparse ground measurements is difficult [1]. Temporal resolution is particularly important for predicting adequate surface wetting and drying between precipitation events and is closely integrated with CADRE. This work aims at improving the PECAD surface and sub-surface soil moisture estimates by assimilating satelliteretrieved soil moisture estimates into the CADRE two-layer soil moisture within an Ensemble Kalman Filter (EnKF) framework.

Soil moisture observations from the Eos Advanced Microwave Scanning Radiometer (AMSR-E) are integrated into the PECAD soil moisture model via a data assimilation system. Surface soil moisture dynamics observed by AMSR-E update the root zone through the vertical soil moisture coupling of the 2-layer soil moisture model. The improved temporal resolution and spatial coverage of the satellite-based EOS Advanced Microwave Scanning Radiometer (AMSR-E) over station data and model outputs

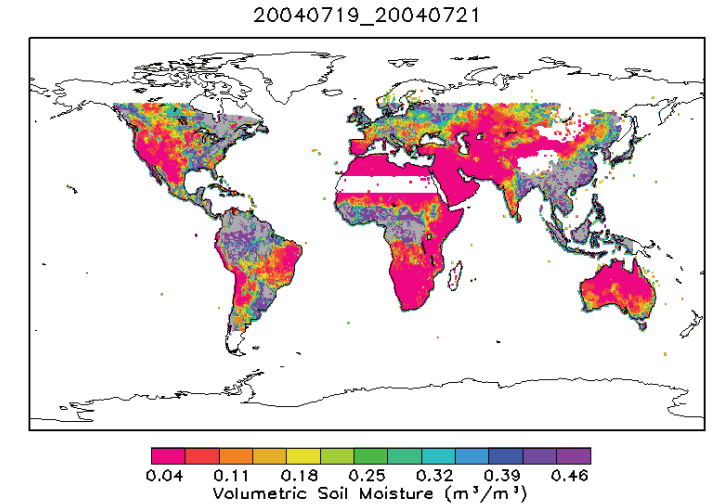

Figure 1. A 3-day composite of the first layer PECAD soil moisture product. 
used by PECAD is expected to provide a better characterization of surface wetness and enable more accurate crop monitoring in key agricultural areas.

\section{PECAD WATER BALANCE MODEL}

The PECAD DBMS combines many data sources including over 3000 ground observations from the World Meteorological Organization and agrometeorological estimates provided by the Air Force Weather Agency (AFWA). Daily estimates of minimum and maximum temperature and precipitation are applied to a modified Palmer two-layer soil moisture model which calculates the daily amount of soil moisture withdrawn by evapotranspiration and replenished by precipitation [4]. FAS has improved upon the original Palmer model by replacing the Thornthwaite evapotranspiration equation with the modified FAO PenmanMonteith equation as described in [5]. Moisture is depleted from the both layers at a fraction of the potential evapotranspiration rate dependant upon surface and root zone capacity and moisture content. Excess water is lost from the system (i.e., no runoff is implied). The model assumes a top soil layer of $2.5 \mathrm{~cm}$ and a second layer max depth of $1 \mathrm{~m}$ or less, dependent upon total water holding capacity derived from the FAO Digital Soil Map of the World, soil texture and depth of the soil column [6]. PECAD applies the Palmer model at daily time steps within a stereographic projection with approximately $47 \mathrm{~km}$ horizontal grid spacing at 60 degree latitude (i.e., $1 / 8^{\text {th }}$ mesh). A 3-day composite of the PECAD soil moisture product is shown in Figure 1.

\section{AMSR-E}

This work applies daily soil moisture estimates from the satellitebased AMSR-E instrument. AMSR-E is a conically-scanning microwave radiometer designed specifically for detecting soil moisture within the top $3 \mathrm{~cm}$ of soil depth [7]. It was launched in 2002 on board the Aqua satellite, and provides full global coverage every 2-3 days. The NASA-delivered soil moisture product provided by AMSR-E is produced from brightness temperatures at 10.65 and $18.7 \mathrm{GHz}$. Observations of soil moisture are calculated from Polarization Ratios (PR) at 10.7 and $18.7 \mathrm{GHz}$, and three empirical coefficients used to compute a vegetation/roughness parameter for each grid cell. Deviations from a $18.7 \mathrm{GHz}$ PR baseline value for each grid cell are used to calculate daily soil moisture estimates for each grid cell [8]. Estimates of soil moisture are provided at a re-gridded global cylindrical $25 \mathrm{~km}$ Equal-Area Scalable Earth Grid (EASE-Grid) cell spacing. These soil moisture estimates are assumed represent a soil depth comparable to the first layer soil moisture used by the PECAD DBMS.

AMSR-E soil moisture estimates have been shown to be prone to low dynamic range and bias. In order to reduce the differences between the Palmer model outputs and AMSR-E observations, each dataset was scaled to a common climatology (the Palmer model). A retrospective analysis of archived AMSR-E and PECAD datasets from June 2002 to June 2007 was performed to establish a representative climatology for both AMSR-E and PECAD soil moisture estimates. Based on these climatologies, a

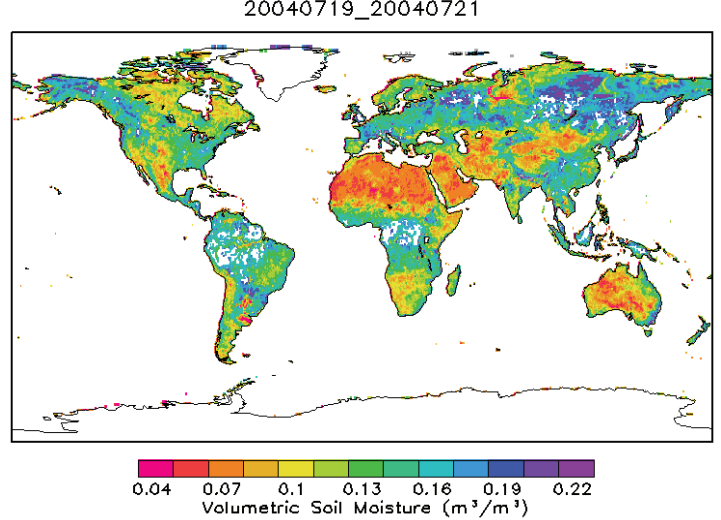

Figure 2. A 3-day composite of AMSR-E soil moisture.

cumulative distribution function (CDF) matching algorithm [9] was employed to transform individual AMSR-E retrievals such that their transformed climatology is comparable to that of PECAD surface soil moisture estimates. The climatologically re-scaled AMSR-E data were then applied to an Ensemble Kalman Filter (EnKF) using sequential observations of AMSR-E, AFWA, and WMO climatological data. Figure 2 illustrates the daily global coverage of the re-scaled Level-3 soil moisture product.

\section{ENSEMBLE KALMAN FILTER}

The increased availability of a multitude of remote sensing products has been shown to be beneficial for improving meteorological, oceanographic, and land surface predictions [10, 11]. Data assimilation techniques use auto-recursive analyses to optimally merge model estimates with state observations. The reduction in model uncertainty is achieved by taking advantage of model state temporal constancy restraints and model physical properties.

Data assimilation is based on the availability of an observation $y$ that can be related to the state vector $x$ via a known observation operator $H$

$$
y_{k}^{i}=H_{k}\left(x_{k}^{i}\right)+v_{k}
$$

where $v_{k}$ represents a random perturbation of observation. Such perturbations are assumed to be Gaussian with a known covariance of $R$.

In this study, a 1-dimensional Ensemble Kalman filter (EnKF) is applied. The EnKF is a nonlinear extension of the standard Kalman filter and has been successfully applied to land surface forecasting problems [12]. Within the filter, sequential ensembles of stochastically perturbed model trajectories are corrected towards an observation of model state when available. The error covariance of both the forecasted observations - or $H_{k}\left(x_{\mathrm{k}}^{\mathrm{i}}\right)-\left(C M_{k}\right)$ and the cross-correlation between these observations and each forecasted state variable $\left(C Y M_{k}\right)$ are calculated by sampling across the an ensemble created by the Monte Carlo realization of (3). 
The updating step of the EnKF utilizes this error covariance information to optimally update forecasts in response to observations, based on the calculation of the Kalman gain as

$$
K_{k}=\frac{C Y M_{k}}{\left(C M_{k}+R\right)}
$$

and the application of the Kalman filter updating equation individually to each realization within the ensemble

$$
x_{k}^{i,+}=x_{k}^{i,-}+K_{k}\left\lfloor y_{k}^{i}-H_{k}\left(x_{k}^{i,-}\right)+v_{k}^{i}\right\rfloor .
$$

where "_" and "+" notation is used to signify state estimates made before and after updating in response to observations at time $k$. The EnKF state estimate at time $k$ is given by simply taking the mean of this updated ensemble.

\subsection{Filter Tuning}

The accuracy of remotely sensed passive microwave observations vary greatly over different land cover types due to signal attenuation by vegetation and increased scattering over rough terrain [13]. At the wavelengths used by AMSR-E, the accuracy of observed soil moisture is significantly degraded over areas of vegetation water content greater than approximately $8-10 \mathrm{~kg} / \mathrm{m}^{2}$ [14]. To reduce errors introduced into the assimilation system from incorrect AMSR-E observations over heavily vegetated areas, we exploit this relation by adjusting the magnitude of the errors applied to the state observations in relation to vegetation type.

A diagnostic calibration of the filter was performed for three ranges of vegetation using filter innovation statistics. A land cover mask was used to adjust the observation error for 1) evergreen and deciduous forests 2) wooded grasslands and mixed forests, and 3) bare soil, grasses and open shrub land. The mean value of observation error that satisfied the innovation statistics for each land cover type was then applied to all global areas possessing a similar land cover type. This method ensures that the filter is placing the proper relative weight on model predictions and remote sensing observations when calculating an analysis soil moisture product with minimized error [15]. A 3 day composite of the same time period as Figures 1 and 2 is shown in Figure 3.

\section{EXPERIMENT DESCRIPTION AND RESULTS}

For evaluation of the data assimilation system, we focus on a 5 year (06/19/2002 - 06/19/2007) analysis of the assimilated product over the conterminous United States. A data denial framework is employed to test the filter performance by comparing two model runs: one forcing the model with 'bad' error-prone precipitation, and another forced with 'good' benchmark precipitation.

The data denial approach is based on three separate model runs over a five-year duration at daily time steps within CONUS. The individual model runs were forced by 1) reliable precipitation (i.e. benchmark loop) 2) error-prone precipitation (i.e. open loop) and 3) error-prone precipitation and the EnKF assimilation of AMSR-E soil moisture retrievals (i.e. EnKF loop). In this way, the application of the EnKF to assimilate remotely-sensed soil moisture retrievals in case 3 can be evaluated based on how efficiently it transformes the low-accuracy results in case 2 (generated with the least accurate rainfall product) to match benchmark results in case 1 (generated using the most accurate rainfall product).

Figure 4 shows spatial maps of the forecasted first layer soil moisture over CONUS on 07/21/2004 for all three schemes discussed above (open loop in Figure $4 \mathrm{a}$, benchmark run in Figure $4 \mathrm{c}$ and the AMSR-E/error-prone/EnKF run in Figure 4d). Also shown is a spatial map of the scaled AMSR-E soil moisture product for the same time period (Figure 4b). It is apparent when comparing $4 \mathrm{a}$ and $4 \mathrm{~d}$ that the assimilation of AMSR-E soil moisture via the EnKF adds spatial heterogeneity to the open loop case. The added heterogeneity allows the EnKF case to better approximate soil moisture patterns in the benchmark case (Figure 4a) by adding soil moisture in areas (e.g. the south-central and northeastern CONUS) where the error-prone product underestimates antecedent precipitation magnitudes. This demonstrates that the AMSR-E soil moisture retrievals are able to effectively compensate modeled soil moisture for the impact of poorly observed rainfall patterns. It is worth noting that over many important - but data poor - agricultural regions of the world, such compensation is critically important due to the lack of ground-based rainfall observations.

These initial results are promising. Evaluation and updates to the system are ongoing, with emphasis on a thorough quantitative analysis of improved performance within the root-zone over specific data-poor regions. Output from this system is currently being operationally delivered to the PECAD DBMS in near real-time.

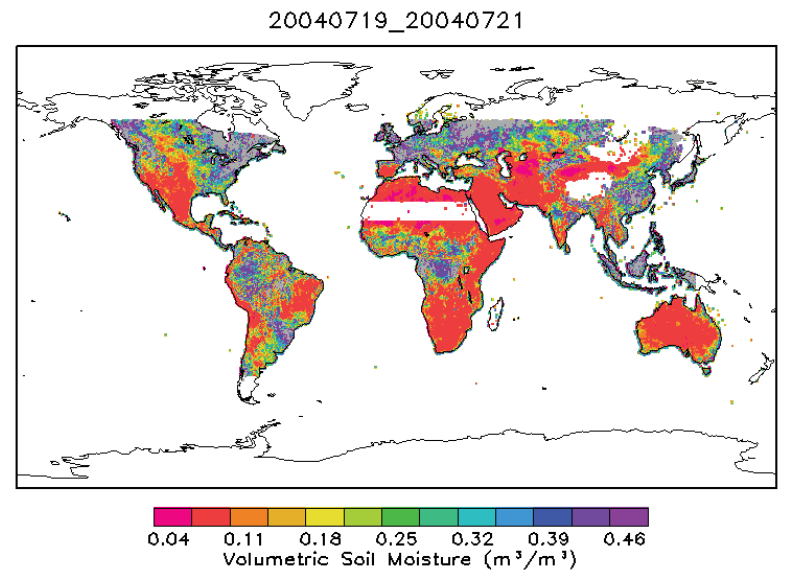

Figure 3. A 3-day composite of the EnKF product for the same time period as Figures 1 and 2. 
A)

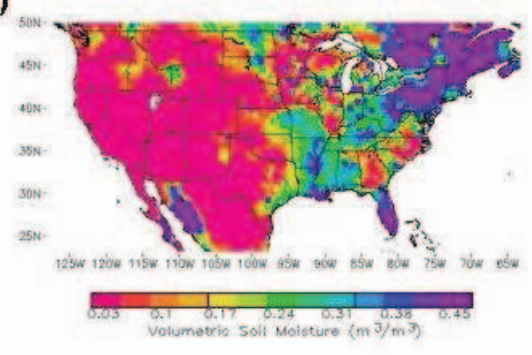

C)

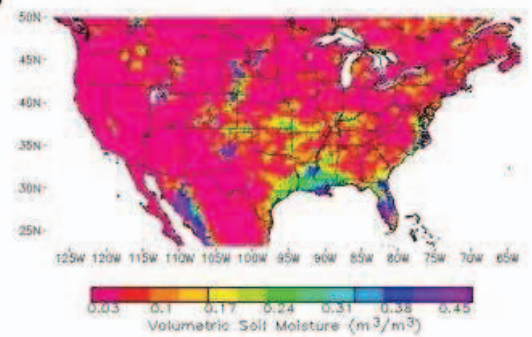

B)

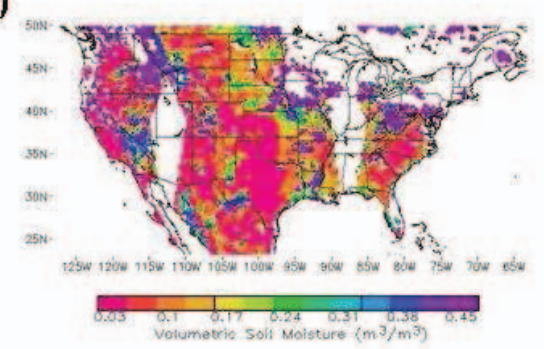

D)

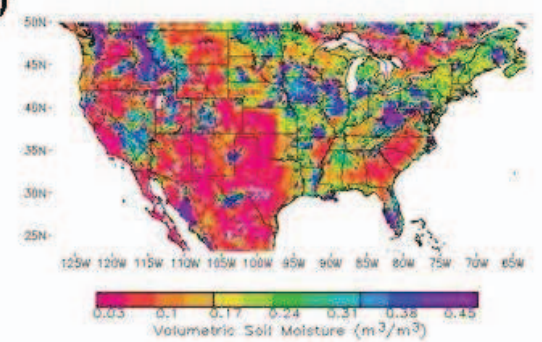

Figure 4. Data denial experiment results over CONUS for 07/21/2004. A) Benchmark loop B) re-scaled AMSR-E Soil moisture product C) Open loop and D) EnKF results.

\section{REFERENCES}

[1] D. Tilman, J. Fargione, B. Bolff, C.D’Antonio, A. Dobson, R. Howarth, D. Schindler, W.H. Schlesinger, D. Simberloff, D. Swackhamer, "Forecasting Agriculturally Driven Global Environmental Change," Science, 292, 281-284, 2001.

[2] C. Rosenzweig, and D. Hillel, "Global warming and agriculture," In Perspectives in World Food and Agriculture, Volume 2. J.A. Miranowski and C.G. Scanes, Eds. Blackwell Publishing, pp. 183-209, 2005.

[3] K.L. Brubaker and D. Entekhabi, "Analysis of feedback mechanisms in land-atmosphere interaction," Water Resour. Res., 325, 1343-1357, 1996.

[4] W.C. Palmer, "Meteorological drought" U.S. Weather Bureau Research Paper 45, 58 pp.,1965.

[5] R.G. Allen, "A Penman for all seasons," J. Irrig. Drain. Eng. 112 (1986), 348-368, 1986.

[6] C.A. Reynolds, T.J. Jackson, and W.J. Rawls. . "Estimating Soil Water-Holding Capacities by Linking the FAO Soil Map of the World with Global Pedon Databases and Continuous Pedotransfer Functions," Water Res. Res., Vol. 36, No. 12, pp. 3653-3662, 2000.

[7] T. Kawanishi, T. Sezai, Y. Ito, K. Imaoka, T. Takeshima Y. Ishido, A. Shibata, M. Miura, H. Inahata, R. Spencer, "The Advanced Microwave Scanning Radiometer for the Earth Observing System (AMSR-E), NASA's contribution to the EOS for global energy and water cycle studies," IEEE Trans. on Geosci. and Rem. Sens. 41, 184194, 2003.

[8] E.G. Njoku, T.J. Jackson, V. Lakshmi, T.K. Chan, and S.V. Nghiem, "Soil moisture retrieval from AMSR-E," IEEE Trans. Geosci. Rem. Sens., 41, 2, 215-229, 2003.
[9] R.H. Reichle and R.D. Koster, "Bias reducton in short records of satellite soil moisture," Geoph. Res. Let., 31, L19501, doi10.1029 /2004GL020938 2004.

[10] W. Crow, and E. Wood, "The assimilation of remotely sensed soil brightness temperature imagery into a land surface model using ensemble kalman filtering: A case study based on ESTAR measurements during SGP97," Adv. in Wat. Res., 26, 137-149, 2003.

[11] D. McLaughlin, A. O'Neill, J. Derber, and M. Kamachi, "Opportunities for enhanced collaboration within the data assimilation community," Quar. J. of the Royal Met. Soc., 131, 3683-3693, 2005.

[12] R.H. Reichle, D.B. McLaughlin, D. Entekhabi,. "Hydrologic data assimilation with the Ensemble Kalman Filter". Mon. Weat. Rev., 130, 103-114,2002.

[13] T.J. Jackson, and T.J. Schmugge, "Vegetation Effects on the Microwave Emission of Soils," Rem. Sen. of Envir., 363, 203-212, 1991.

[14] F.T. Ulaby and A.K. Fung, "Microwave remote sensing: Active and passive-volume I scattering and emission theory, advanced systems and applications,” Dedham, MA: Artech House, 1986.

\section{ACKNOWLEDGEMENTS}

This research was supported by funding from NASA's Applied Sciences Program and grant NNS06AA051 entitled "Integrating NASA's Global Soil Moisture Remote Sensing and Modeling Data into the USDA's Global Crop Production Decision Support System" 